\title{
CONTABILIDADE E SUSTENTABILIDADE NOS ENANPADS: 2010-2016
}

Data de submissão: 22/09/2017 Aceite: $17 / 07 / 2018$

Fernanda da Silva Momo ${ }^{1}$ Marcos Vinícius Araujo²

Ariel Behr ${ }^{3}$

\section{RESUMO}

A partir das preocupações com o meio ambiente, surgiu, na Organização das Nações Unidas, uma comissão para discutir sustentabilidade e desenvolvimento sustentável, da qual emergiram diversas outras pesquisas, relatórios e materiais de uso acadêmico e de uso em políticas públicas. Nesse sentido, o tema se tornou importante e tem sido estudado em diversas áreas, como na Contabilidade e na Administração, ganhando, inclusive, sessões temáticas em eventos, como o Encontro da Associação Nacional de Pesquisa em Administração (EnANPAD), maior evento brasileiro da área. Visto esse ganho de importância, este trabalho tem por objetivo analisar os artigos publicados na linha Contabilidade e Sustentabilidade, de 2010 a 2016. Para tal, coletou-se todos os artigos para uma análise quantitativa, a partir de uma análise frequencial, utilizando-se o software $\mathrm{NVivo}^{\circledR}$. Os resultados mostram as palavras e temas mais comuns nos títulos e resumos. A partir dos resultados, é possível concluir que há uma diversidade de abordagens direcionadas a essa temática, mas percebe-se que as publicações possuem um enfoque em temas de mensuração e divulgação das ações relacionadas à sustentabilidade. Assim, dentro da abordagem contábil, a sustentabilidade está relacionada a pensar no futuro da organização e sua imagem, ou seja, à divulgação de seus resultados.

Palavras-chave: Sustentabilidade; contabilidade; relatório de sustentabilidade; indicadores de sustentabilidade.

\footnotetext{
1 Possui graduação em Ciências Contábeis pela Universidade Federal do Rio Grande do Sul, UFRGS, mestrado em Administração pela UFRGS e doutorado em andamento em Administração pela UFRGS. Porto Alegre - Rio Grande do Sul. Brasil. E-mail: fernandamomo@yahoo.com.br 2 Possui graduação em Comunicação Social - Publicidade e Propaganda pela Universidade Federal de Goiás, UFG, mestrado em Agronegócios pela Universidade Federal do Rio Grande do Sul, UFGRS e doutorando em andamento em Agronegócios pela UFRGS. Porto Alegre - Rio Grande do Sul. Brasil. E-mail: araujovmarcos@gmail.com

3 Possui graduação em Ciências Contábeis pela Universidade Federal do Rio Grande do Sul, UFRGS, mestrado em Administração pela UFRGS e doutorado em Administração pela UFRGS. Porto Alegre - Rio Grande do Sul. Brasil. E-mail: ariel.behr@ufrgs.br
} 


\section{INTRODUÇÃO}

A sustentabilidade vem ganhando atenção em diversas áreas do conhecimento, seja pelos reflexos positivos quanto à agregação de valor, seja como resposta a eventos climáticos que tornam cada vez mais relevantes os estudos voltados a essa temática. Dentro da agenda 2030 da Organização das Nações Unidas, o desenvolvimento sustentável não só vem sendo foco em empresas, que o empregam por uma pressão dos consumidores, mas também ganha escopo em pesquisas de diversos temas. A agenda propõe um plano de ações apresentadas em 17 objetivos para o desenvolvimento sustentável em áreas de grande importância para a humanidade, focando nas pessoas, no planeta, na prosperidade e nas parcerias para que o plano seja possível (ONU$B R, 2015)$. Muitas dessas questões, que partem de preocupações despontadas de problemas como as mudanças climáticas, mostram a vulnerabilidade do planeta frente às ações humanas.

O principal objetivo do desenvolvimento sustentável é atender as necessidades humanas e buscar uma vida melhor dentro de limites ecológicos para que todos possam ter acesso e que contribuam para o crescimento sem explorar a outros. Ou seja, precisa promover a igualdade entre as pessoas, buscar uma harmonia entre uso dos recursos disponíveis, crescimento econômico e sociedade, para que seja possível satisfazer as necessidades humanas (UNITED NATIONS, 1987).

Assim, os temas envolvendo a sustentabilidade também ganharam espaço em pesquisas e eventos de diversas áreas, como nas ciências contábeis e administrativas. Dentro desse escopo, desde 2010 a Associação Nacional de Pesquisa em Administração (ANPAD) conta com a divisão temática Contabilidade e Responsabilidade Socioambiental, a qual aborda temas econômico-financeiros relacionados à sustentabilidade.

A partir dessa agenda de pesquisa proposta pela ANPAD, questiona-se quais temas das publicações do Encontro da Associação Nacional de Pesquisa em Administração (EnANPAD) envolvem a linha de Contabilidade e Sustentabilidade. Para responder a essa questão, foram analisados, quantitativa e qualitativamente, os artigos publicados nos anais desse evento publicados de 2010 a 2016, com o objetivo de destacar os temas das publicações do EnANPAD que envolvem essa temática nesse período.

\section{REFERENCIAL}

Nesta seção, será abordado, inicialmente na seção 2.1, o conceito de sustentabilidade, de forma a apresentar brevemente sua definição e seu referencial histórico. Posteriormente, enfoca-se, na seção 2.2, o tema do desenvolvimento sustentável e os indicadores de sustentabilidade. Por fim, a seção 2.3 descreve o evento EnANPAD e sua relevância para a área de administração e contabilidade.

\subsection{SUSTENTABILIDADE}

A sustentabilidade é um tema abrangente, de forma a não se limitar a uma linha e a uma área de formação; sendo assim, atualmente esse conceito está sendo discutido por autores de diferentes áreas do conhecimento. Em relação ao estudo desse tema, destaca-se que houve uma intensificação de estudos nas décadas de 1980 e 1990 devido ao 
aumento da preocupação com a questão ambiental. Preocupação esta, que diz respeito ao intenso processo de degradação generalizada do meio ambiente e dos recursos naturais, provocados pela intensificação do crescimento econômico e populacional ocorridos no século XX (DALMORO, 2009, p. 89).

Assim, vários autores afirmam que o termo "desenvolvimento sustentável" surgiu nesse período e pode ser compreendido como o desenvolvimento no qual são levadas em consideração as futuras gerações. O documento Future (Nosso Futuro Comum) foi elaborado pela Comissão Mundial sobre Meio Ambiente e Desenvolvimento, criada pela Organização das Nações Unidas (ONU), e apresentou formalmente esse conceito. Ainda sobre essa comissão, que formalizou nesse documento um conceito de desenvolvimento sustentável, destaca-se que isso ocorreu no ano de 1983 e, nesse ano, a médica Gro Harlem Brundtland, ?]mestre em saúde pública e ex-Primeira Ministra da Noruega [foi convidada] para estabelecer e presidir essa comissão? (ONU, 2017).

Essa comissão foi resultado da reunião realizada em Estocolmo, em 1972, na qual também foi criado o Programa das Nações Unidas para o Meio Ambiente. Outras importantes reuniões se sucederam a partir dessa, como a Eco92, realizada no Rio de Janeiro, além de outras conferências que tiveram o desenvolvimento sustentável como tema principal dos debates. A sustentabilidade, então, tornou-se uma área de interesse não só científico e público, mas também político, visto o envolvimento de governantes nessas discussões.

\subsection{DESENVOLVIMENTO SUSTENTÁVEL E INDICADORES DE SUSTENTABILIDADE}

O conceito de desenvolvimento sustentável foi construído a partir do desenvolvimento econômico, passando primeiro pela economia sustentável, para então desenvolvimento sustentável, com a inclusão do social e da ética, que leva em consideração fatores ambientais e institucionais, pautados por sua viabilidade econômica (RODRIGUES; RIPPEL, 2015). Para que seja possível atender a essa relação entre meio ambiente, sociedade e viabilidade econômica, outras áreas foram agregadas, pensando nos objetivos do desenvolvimento sustentável.

Nesse sentido, conforme Colglazier (2015), ciência, tecnologia e inovação são vistas dentro dos objetivos do desenvolvimento sustentável para 2030. Ainda segundo o autor, essas áreas apresentam contribuições como mostrar desafios e/ou ações que fazem a diferença, monitorar o progresso e trazer soluções inovadoras. Essa avaliação e essa elucidação de progressos e desafios podem ser apresentadas através de indicadores de sustentabilidade.

Contudo, é necessário prudência ao propor indicadores e critérios, já que isso pode afetar positiva ou negativamente organizações, a partir da percepção de informações falsas (BILGIN, 2012) ou inadequadas. A partir disso, para mensurar o desenvolvimento sustentável, é preciso ir além do PIB (Produto Interno Bruto) e considerar aspectos como: bem-estar social, prosperidade, crescimento econômico e desenvolvimento ambiental, que podem ser avaliados com a pegada ecológica, com a pegada hídrica, com os Indicadores de Referência Europeu, com o índice de bem-estar econômico sustentável significativo e com outros índices (ALEXANDRA; DOREL, 2016), como o índice de desenvolvimento sustentável, proposto por Waquil et al., (2010), que avalia o desenvolvimento territorial sustentável a partir das dimensões social, ambiental, econômica, demográfica, político-institucional e cultural.

Além desses índices, o Instituto Brasileiro de Geografia e Estatística (IBGE), alinhado com a agenda global de desenvolvimento sustentável, que se originou no Rio de Janeiro na Eco92desenvolveu seu próprio índice para mensurar o desenvolvimento sustentável, que fornece informações como uso de recursos naturais, qualidade ambiental, satisfação das necessidade humanas, qualidade de vida, justiça social, desempenho econômico e financeiro e uso de energia (IBGE, 2012). 
A variedade de indicadores e a complexidade em explorar esses dados, seja pela quantidade, seja pela falta ou imprecisão nas coletas, dificulta os processos de análise, tabulação e, principalmente, formulação de metodologias para apresentar e comunicar esses índices, o que leva os pesquisadores a desenvolverem índices baseados nos existentes para conseguir mensurar o desempenho de sustentabilidade com os dados disponíveis.

\subsection{ENCONTRO NACIONAL DA ASSOCIAÇÃO NACIONAL DE PÓS-GRADUAÇÃO E PESQUISA EM ADMINISTRAÇÃO}

O EnANPAD é um encontro promovido pela Associação Nacional de Pós-Graduação e Pesquisa em Administração (ANPAD), uma instituição que representa as áreas de administração e contabilidade. Esse evento é realizado com uma periodicidade anual e é reconhecido por profissionais e acadêmicos dessas áreas de conhecimento (ANPAD, 2017). O evento esteve em sua quadragésima primeira edição no ano de 2017 e se apresenta como um espaço que estimula o debate e interação entre os participantes (ANPAD, 2017).

Esse debate torna-se importante uma vez que todo texto publicado em anais de evento científico é um texto provisório - workingpaper, mesmo que decorrente de pesquisa concluída. Tipicamente, a partir dos debates e das críticas recebidas durante o evento, o autor terá informações importantes para aperfeiçoar seu manuscrito e submetê-lo a um periódico, dando sequência ao processo de divulgação científica. Além disso, o EnANPAD proporciona a oportunidade de interação social entre pares, de modo a alavancar a formação e o fortalecimento de redes de pesquisa. (ANPAD, 2017).

Assim, tendo em vista que o objetivo central da ciência é gerar e divulgar resultados das pesquisas de forma a impulsionar o saber (DIAS; BARBOSA NETO; CUNHA, 2011), eventos como o EnANPAD tem papel relevante no que se refere ao fomento da qualidade de pesquisas na área de administração e contabilidade, assim como no avanço do conhecimento dessa área. Por fim, destaca-se que esse evento está organizado em Divisões Acadêmicas, que são constituídas por Temas de Interesse relacionados a essas divisões.

Nesse sentido, tendo em vista a temática abordada neste artigo, enfoca-se na Divisão Acadêmica de Contabilidade o Tema Contabilidade e Sustentabilidade. Essa linha do congresso tem como foco temas relativos a aspectos econômico-financeiros da sustentabilidade, como: "gestão ambiental; contabilidade ambiental; aspectos contábeis e comerciais de créditos de carbono; gestão da responsabilidade social corporativa; relatórios sociais; demonstração do valor adicionado; indicadores sociais e ambientais, e responsabilidade cultural" (ANPAD, 2017).

Depois dessa apresentação do congresso EnANPAD e de sua relevância para as áreas de administração e contabilidade, apresentam-se a seguir os procedimentos metodológicos adotados neste estudo.

\section{MÉTODO}

Em relação ao método, haja vista o objetivo da pesquisa de explorar a produção acadêmica do congresso EnANPAD, mais especificamente na linha de pesquisa de Contabilidade e Sustentabilidade no período de 2010 a 2016, o presente estudo pode ser considerado quanto a sua natureza quantitativa. Além disso, quanto aos objetivos, a pesquisa classifica-se como descritiva uma vez que descreve as características de uma amostra que, neste artigo, são os estudos apresentados no EnANPAD em um período e tema determinados. Por fim, em relação aos 
procedimentos técnicos, pode ser entendida enquanto uma pesquisa bibliográfica, tendo como dados,como suporte às afirmações a serem feitas, uma base de material já elaborado, constituída principalmente de livros e artigos científicos (GIL, 2008).

Nesse sentido, destaca-se que as unidades de análise da pesquisa em questão foram artigos publicados no congresso EnANPAD na linha de Contabilidade e Sustentabilidade no período de 2010 a 2016. Assim, de forma a tornar o procedimento de coleta de dados um processo transparente, explícito e reprodutível (MUÑOS, 2009), apresenta-se, no Anexo A, uma tabela que contém os nomes dos artigos, o ano das publicações e os autores. Ainda em relação à coleta dos dados, destaca-se que, dos 38 artigos apresentados no congresso na linha de pesquisa selecionada, não foi possível conseguir acesso ao texto completo de um dos artigos. Portanto, nesse caso, as análises se limitaram ao conteúdo exposto no título e resumo.

A análise dos dados se deu a partir da análise de conteúdo (BARDIN, 2011), empregando a categorização por meio da contagem frequencial, e interpretando o significado dessas palavras quando associadas em conjuntos. Utilizou-se, nesta etapa, o software NVivo ${ }^{\circledR}$, versão 11 , a fim de operacionalizar a contagem frequencial e a associação de palavras em conjuntos. No que se refere àcontagem frequencial, utilizou-se todas as palavras dos títulos e resumos. Optou-se por não incluir, na análise de frequência, as palavras chaves dos artigos, pois havia textos que não as continham. Na seção a seguir, são apresentadas as análises dos resultados da pesquisa.

\section{ANÁLISES}

Em relação a um perfil inicial dos 38 artigos selecionados, observa-se que todos foram publicados na língua portuguesa e a maioria dessas pesquisas $(34,21 \%)$ foram publicadas no ano de 2011. Além disso, observa-se que a média de publicações nessa temática é de 5,42 artigos e a mediana é de 5 artigos, de forma que a quantidade de publicações feitas no ano de 2011 não afeta a representatividade do resultado apresentado pela média. Por fim, destaca-se ainda que 2013 teve apenas um artigo apresentado nessa linha de pesquisa e foi, portanto, o ano com a menor quantidade de artigos publicados no período analisado. A seguir, apresenta-se o Gráfico1 com a quantidade de publicações por ano.

\section{Gráfico 1 - Publicações por ano}

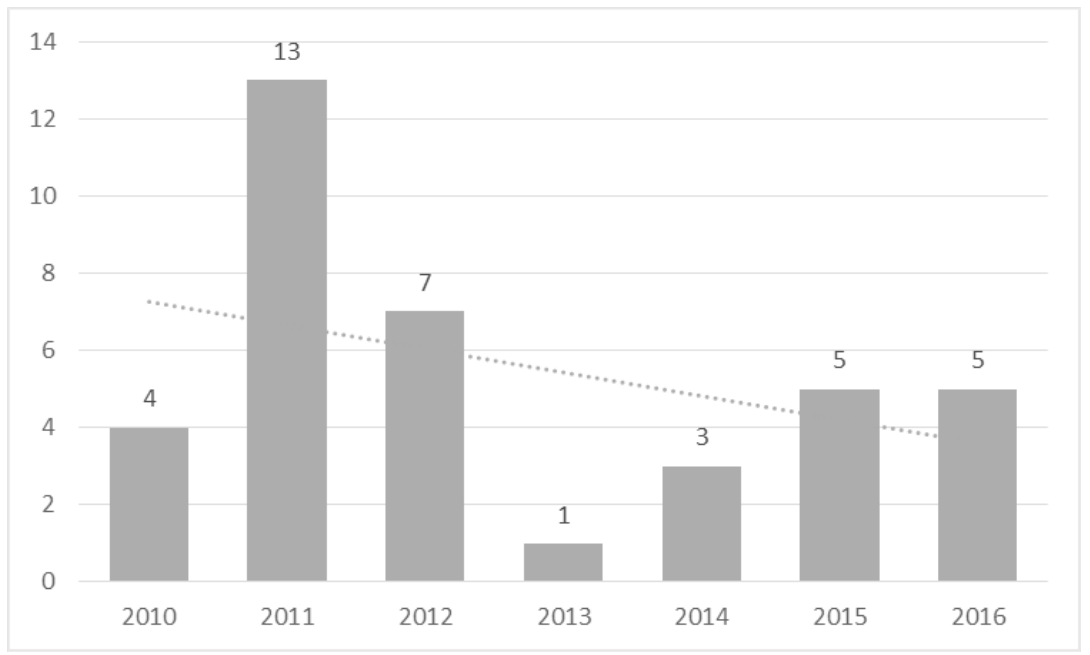

Fonte: Elaborado pelos autores. 
Em relação à autoria dos artigos, realizou-se a contagem da quantidade de autores. A partir dessa análise,verificou-se que, na grande maioria das vezes, as publicações são realizadas por dois, três e quatro autores. Mesmo assim, foi possível identificar três artigos com apenas um autor e, desses três artigos, dois tem o mesmo autor. Além disso, há dois artigos com cinco autores, sendo um deles de 2010 e o outro de 2015. A Tabela 1 a seguir ilustra bem essa análise.

Tabela 1 - Quantidade de autores nos artigos

\begin{tabular}{c|c|c|c|c|c|c|c|c}
\hline Quantidade de autores & 2010 & 2011 & 2012 & 2013 & 2014 & 2015 & 2016 & Total Geral \\
\hline 1 & - & 2 & 1 & - & - & - & - & 3 \\
\hline 2 & 1 & 4 & 1 & 1 & 2 & 2 & - & 11 \\
\hline 3 & 1 & 3 & 4 & - & - & 1 & 2 & 11 \\
\hline 5 & 1 & 4 & 1 & - & 1 & 1 & 3 & 11 \\
\hline Total Geral & 1 & - & - & - & - & 1 & - & 2 \\
\hline
\end{tabular}

Fonte: Elaborado pelos autores).

Posteriormente a essas análises, foram avaliados os conteúdos dos títulos, resumos e palavras-chaves desses artigos. Assim, será apresentada uma breve análise relativa às palavras e aos temas mais utilizados nessas partes do texto, tendo em vista a frequência com que essas palavras aparecem nessas três partes. A Figura 1 apresenta as 30 palavras mais frequentes nos títulos dos artigos.

Figura 1 - Frequência das palavras dos títulos dos artigos

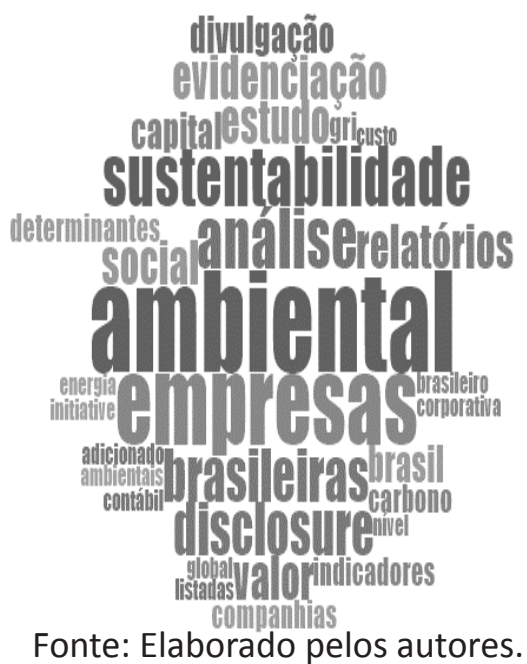

Na Figura 1, é possível observar as 30 palavras mais frequentes nos títulos dos artigos analisados. Dentre essas palavras destaca-se inicialmente as que tiveram uma frequência igual ou superior a 6: ambiental; empresas; análise; sustentabilidade; brasileiras; disclosure; estudo; evidenciação; relatórios; social; e valor. Nessas 11 palavras destacadas, ressalta-se que três delas estão diretamente relacionadas ao tema da sustentabilidade, as quais são: sustentabilidade, ambiental e social. Destaca-se também que outras duas estão relacionadas com o foco em que foram aplicados os estudos, sendo elas: empresas e brasileiras.

Além disso, observa-se que duas estão bem alinhadas com os métodos dos estudos, as quais são: estudo e análise. Por fim, evidencia-se um outro conjunto de palavras, que pode ser caracterizado pelos temas mais frequentes abordados pelos estudos, os quais terão como base o 
grande tema da sustentabilidade: análise, disclosure, evidenciação, relatórios e valor. Essa subdivisão pode ser melhor visualizada na Figura 2.

\section{Figura 2 - Palavras dos títulos dos artigos}
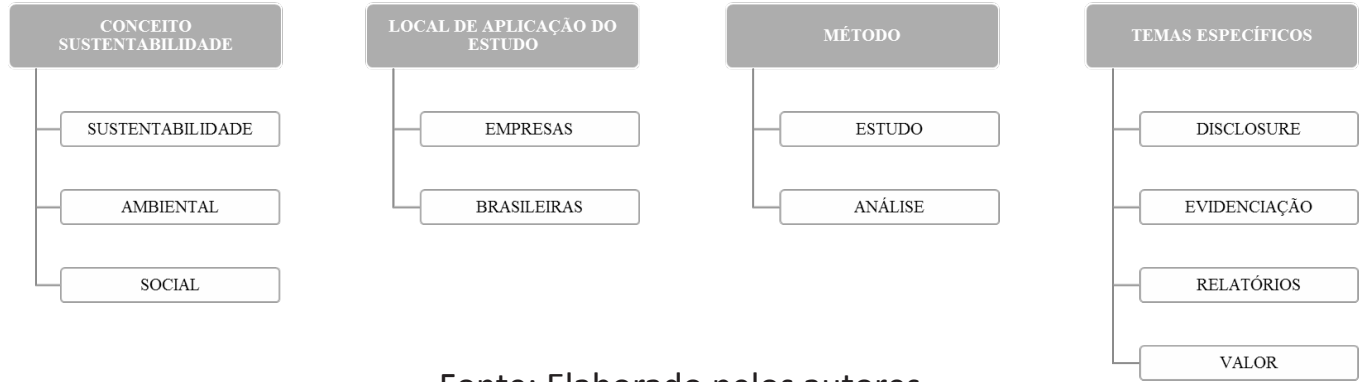

Fonte: Elaborado pelos autores.

Assim, a partir dessa análise, já é possível compreender uma abordagem explorada por esses estudos que evidenciam a questão da transparência, a questão da informação e a explicitação dessas questões em relatórios econômico-financeiros. Outro tópico que deve ser ressaltado é a questão do valor, ou seja, os estudos se preocupam em fomentar o conhecimento da sustentabilidade, alinhados a questão financeira e social. Em relação aos resumos dos artigos, identificou-se os seguintes resultados, conforme Figura 3.

Figura 3 - Frequência das palavras dos resumos dos artigos

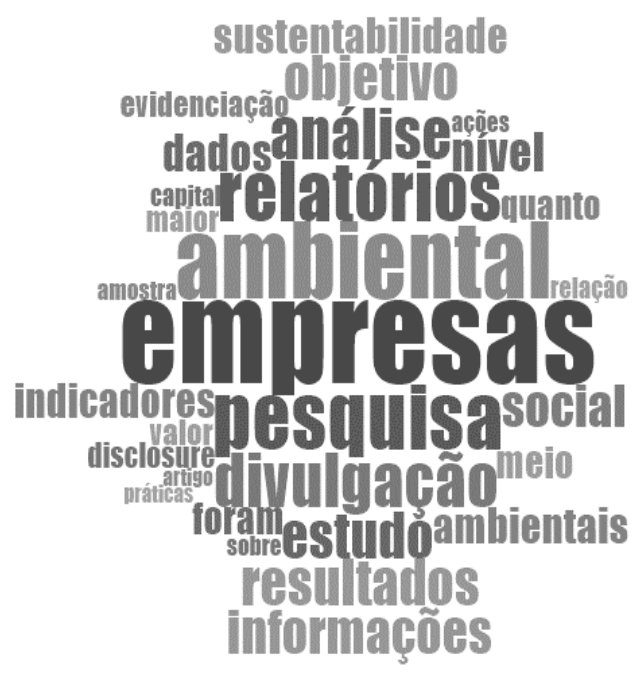

Fonte: Elaborado pelos autores.

Na Figura 3, é possível observar as 30 palavras mais frequentes nos resumos dos artigos analisados. Dentre essas palavras, destacam-se as que tiveram uma frequência igual ou superior a 40: empresas; ambiental; pesquisa; relatórios; divulgação; análise; estudo; resultados; objetivos; informações. É possível identificar que a frequência das palavras é muito maior nesta segunda análise, tendo em vista o tamanho dos resumos se comparados ao dos títulos, mas, além disso, identifica-se que as palavras mais frequentes se referem a estruturas comumente utilizadas nos resumos como, por exemplo, conclusões.

Em relação à análise dos títulos, salienta-se que as palavras novas que surgiram da análise dos resumos foram: pesquisa; resultados; objetivos e informações. Ressalta-se que a palavra 
divulgação é nova, mas possui o mesmo contexto de disclosure e de evidenciação, que já haviam aparecido na análise dos títulos. Por fim, reforça-se que essas novas palavras mais frequentes estão totalmente relacionadas com a estrutura do resumo e não caracterizam de forma específica a abordagem dada pelos autores em seus artigos no que tange a análise das palavras mais frequentes. A Figura 4 apresenta a classificação das 10 palavras que apareceram 40 vezes ou mais nos resumos dos artigos selecionados.

Figura 4 - Palavras dos resumos dos artigos
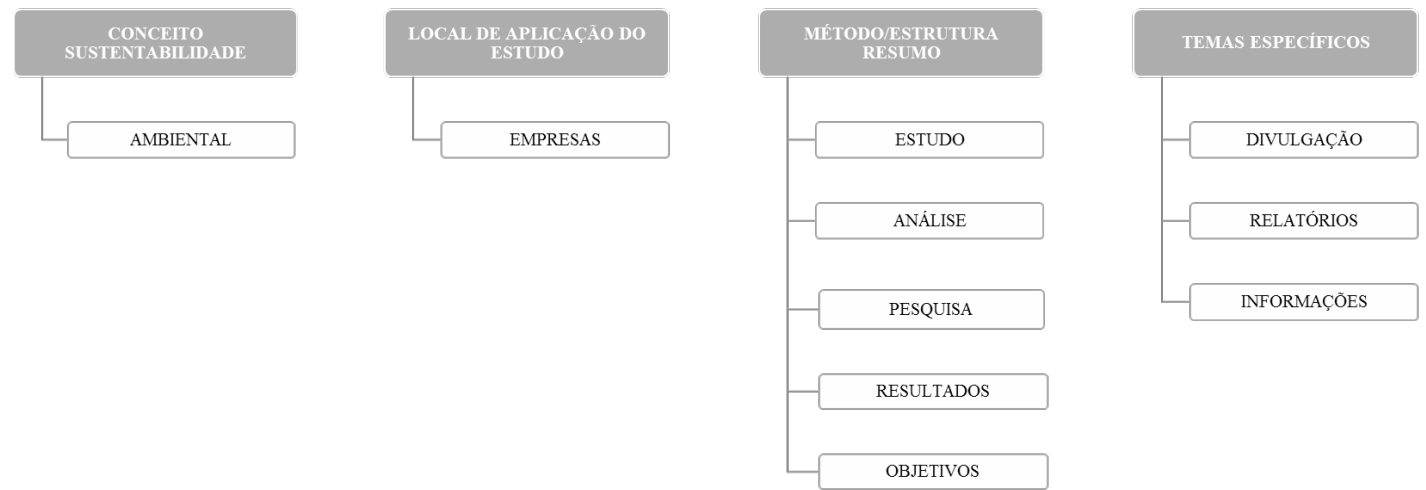

Fonte: Elaborado pelos autores.

Por fim, de forma a consolidar os tópicos levantados a partir da análise de frequência das palavras dos títulos e resumos, apresenta-se a seguir a Figura 5, que consolida as análises realizadas. Nessa figura, ressalta-se que as palavras que estão em caixas cinza apareceram nas duas análises de frequência realizadas, as palavras sublinhadas são as relativas somente aos resumos e as palavras sem nenhuma demarcação apareceram apenas na análise de frequência dos títulos.

Figura 5 - Palavras dos títulos e resumos dos artigos
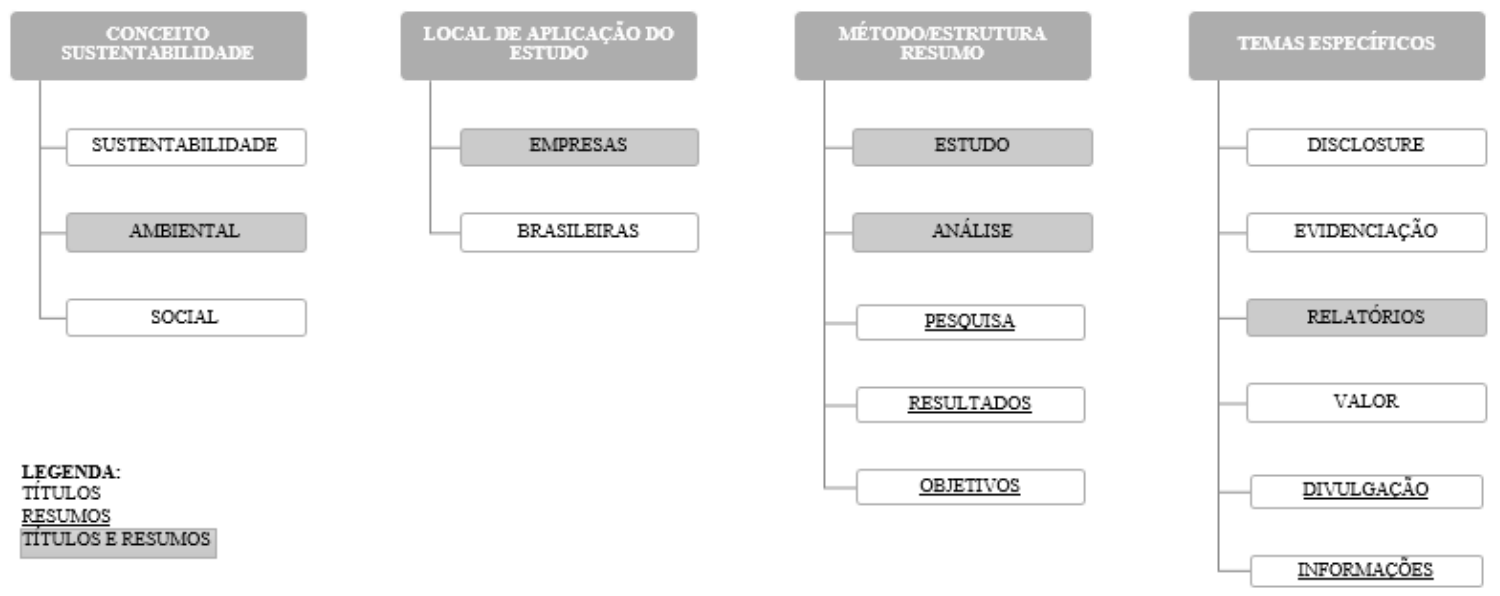

Fonte: Elaborado pelos autores.

Por fim, apresenta-se, na Figura 6, uma análise de cluster realizada a partir dos artigos completos publicados na linha de Contabilidade e Sustentabilidade do EnANPAD. Nessa figura, é 
possível identificar uma subdivisão inicial em dois grandes tópicos abordados pelos artigos, finalizando em seis tópicos que estão ressaltados na figura.

Figura 6 - Análise de Cluster das 20 palavras mais frequentes dos artigos

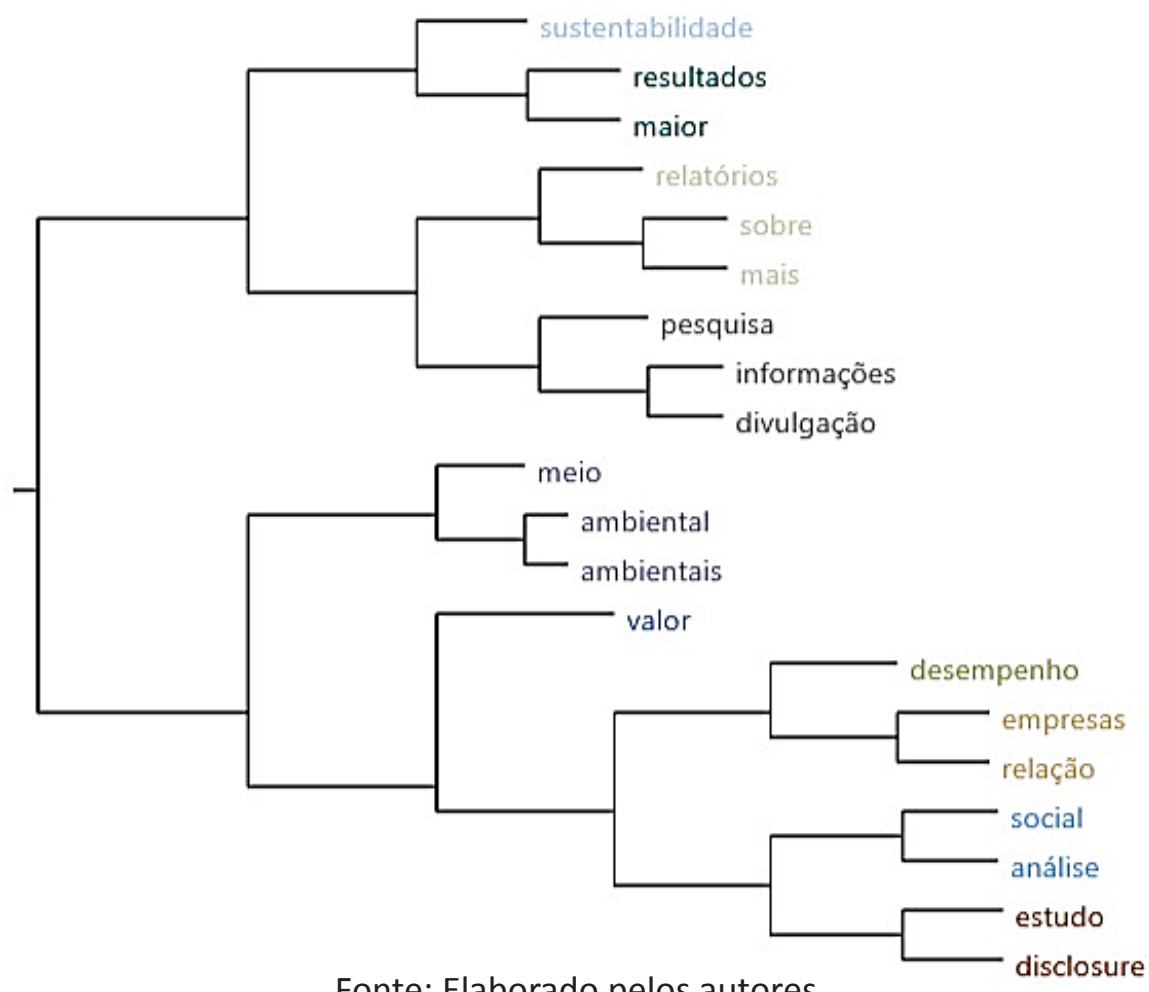

Fonte: Elaborado pelos autores.

Observa-se que os grupos de palavras são compostos, em sua maioria, por três palavras. No Grupo 1, pode-se identificar que a sustentabilidade é abordada em relação as palavras resultados e maior, ou seja, este grupo representa os estudos que possuem um enfoque maior em medir como ações relacionadas a sustentabilidade podem impactar em maiores resultados econômicos. No Grupo 2, a palavra que se destaca é relatórios, a qual se relaciona com os termos sobre e mais, representando, assim, os estudos que possuem o foco na elaboração de relatórios que explicitem as práticas das empresas no que tange à sustentabilidade. No Grupo 3, pode-se auferir que as pesquisas enfocam as informações e a forma de divulgação, em outras palavras, percebe-se que há um grupo de pesquisadores interessados em saber como ocorre a divulgação da informação sobre sustentabilidade pelas empresas e como são elaboradas essas informações. O Grupo 4 refere-se ao tema abordado por este artigo, sendo representado pelas palavras meio, ambiental e ambientais. Por fim, há o Grupo 5 e 6 que estão relacionados ao termo valor. Nesses grupos as pesquisas estão focadas não apenas no valor econômico, mas também nos custos e impactos que podem gerar dispêndio de caixa; possíveis ações que modifiquem o desempenho da organização. $O$ Grupo 5 enfoca o desempenho das empresas e relações associadas ao desempenho. 0 Grupo 6 evidencia duas questões: social e análise, estudo e disclosure. Essas relações podem ser identificadas na Figura 6 e na Figura 7. 
Figura 7 - Análises das 20 palavras mais frequentes dos artigos

\begin{tabular}{|c|c|c|c|c|c|}
\hline $\begin{array}{l}\text { - Sustentabilid } \\
\text { ade } \\
\text { - Resultados } \\
\text {-Maior }\end{array}$ & $\begin{array}{l}\text { - Relatórios } \\
\text { - Sobre } \\
\text { - Mais }\end{array}$ & $\begin{array}{l}\text {-Pesquisa } \\
\text {-Informações } \\
\text { •Divulgação }\end{array}$ & $\begin{array}{l}\text { - Meio } \\
\text { - Ambiental } \\
\text {-Ambientais }\end{array}$ & $\begin{array}{l}\text {-Desempenho } \\
\text { •Empresas } \\
\text { - Relação } \\
\text {-Valor }\end{array}$ & $\begin{array}{l}\text {-Social } \\
\text { - Análise } \\
\text {-Estudo } \\
\text {-Disclosure } \\
\text { - Valor }\end{array}$ \\
\hline
\end{tabular}

Fonte: Elaborado pelos autores.

Portanto, a partir das análises realizadas nessa seção, foi possível identificar um perfil das pesquisas publicadas no congresso EnANPAD, de 2010 até 2016. Verificou-se que os artigos abordam o tema da sustentabilidade e contabilidade a partir, por exemplo, de temas como desempenho, valor, indicadores e disclousure. Assim, a seguir, apresentam-se as considerações finais deste estudo, suas limitações e sugestões para estudos futuros.

\section{CONSIDERAÇÕES FINAIS}

O presente artigo alcançou o objetivo da pesquisa ao identificar e descrever os temas das publicações do Encontro da Associação Nacional de Pesquisa em Administração (EnANPAD), que envolvem a linha de Contabilidade e Sustentabilidade. Para tal, foram analisados, de forma quantitativa e qualitativa, os artigos publicados nos anais desse evento de 2010 a 2016. Sendo assim, ao realizarem-se as análises dos artigos selecionados, foi possível identificar que, em todos os artigos, é enfatizada a importância do tema da sustentabilidade na área da administração e contabilidade.

Observou-se também que há uma diversidade de abordagens nessa temática, mas percebe-se que as publicações possuem um enfoque em temas de mensuração e divulgação de ações relacionadas à sustentabilidade. Assim, notou-se que muitos dos artigos analisados ressaltaram a relevância de temas como o disclosure, de forma a corroborar com a afirmação anterior sobre os temas abordados. Dessa forma, é possível compreender que a sustentabilidade, em uma abordagem contábil, está relacionada a pensar no futuro da organização, em sua imagem e, portanto, é abordar o tema da sustentabilidade a partir do aspecto econômico, social e ambiental; mas, principalmente, em termos de transparência e divulgação da informação pelas organizações. Portanto, essa temática pode ser entendida como relevante, não apenas em termos de custos que ações sustentáveis possam ter, mas também como uma cultura a ser posta em prática pela organização de forma a ser possível, por exemplo, a obtenção de diferenciais competitivos para a organização que possui a sustentabilidade como uma identidade organizacional.

Como limitações dessa pesquisa tem-se, além da série temporal escolhida, questões como as sutilezas das escolhas realizadas para definição do objeto de análise (os artigos), como, por exemplo, a escolha por analisar apenas os artigos constantes no congresso EnANPAD. Entretanto, ressalta-se que essas escolhas realizadas não afetaram o rigor aplicado à pesquisa. Tendo em vista essas limitações, sugere-se para estudos futuros a realização de uma revisão que abarque um período de tempo maior e em outras bases de dados que versem sobre o tema de contabilidade e sustentabilidade. 


\section{REFERÊNCIAS}

ALEXANDRA, A.; DOREL, D. Approaches on measuring sustainable development in contemporary world. Annals of the Constantin Brâncuşi. University of Târgu Jiu. Anais...2016.

ANPAD. Evento EnANPAD, 2017. Disponível em: < http://www.anpad.org.br/ anpad/eventos. php?cod_evento=1\&cod_evento_edicao=83>. Acesso em: 22 jul. 2017.

BARDIN, L. Análise de conteúdo. 1. ed. São Paulo: Edições 70, 2011.

BILGIN, M. The PEARL Model of Sustainable Development. Social Indicators Research, v. 107, p. 19-35, 2012.

COLGLAZIER, W. Sustainable development agenda: 2030. Science, v. 349, n. 6252, p. 4-7, 2015.

DALMORO, M. A visão da sustentabilidade na atividadeempreendedora: uma análise a partir deempresas incubadas. Revista Gestão Organizacional, v. 2, 2009.

DIAS, W. O.; BARBOSA NETO, J. E.; CUNHA, J. V. A. A comunicação do conhecimento científico: dados sobre a celeridade do processo de avaliação e de publicação de artigos científicos em periódicos da área de contabilidade. Revista Contemporânea de Contabilidade, v. 8, n. 15, p. 41-62, 2011.

GIL, A. CARLOS. Métodos e técnicas de pesquisa social. 2. ed. São Paulo: Atlas, 2008.

IBGE, I. B. DE G. E E.-. Indicadores de Desenvolvimento Sustentável - Brasil 2012. 9. ed. Rio de Janeiro: Estudos e Pesquisas Informação Geográfica, 2012.

MUÑOS, D. L. Estudos empíricos de gestão de conhecimento orientados para sustentabilidade: uma revisão sistemática de literatura de 1998 a 2009. Programa de Pós-Graduação de Engenharia e Gestão de Conhecimento da UFSC, 2009.

ONU. Sustentabilidade. Disponível em: < https://nacoesunidas.org/acao/meio-ambiente/ >. Acesso em: 21 jun 2018.

ONUBR. Transformando Nosso Mundo: A Agenda 2030 para o Desenvolvimento Sustentável. Disponível em: <https://nacoesunidas.org/pos2015/agenda2030/>.Acesso em: 21 jun 2018.

RODRIGUES, K. F.; RIPPEL, R. Desenvolvimento Sustentável e técnicas de mensuração. Revista de Gestão Ambiental e Sustentabilidade, v. 4, n. 3, p. 73-88, 2015.

UNITED NATIONS. Report of the World Commission on Environment and Development : Our Common Future Acronyms and Note on Terminology Chairman Foreword.Oslo: [s.n.]. Disponível em: <http://www.un-documents.net/our-common-future.pdf>Acesso em: 21 jun 2018.

WAQUIL, P. et al. Avaliação de Desenvolvimento Territorial em e m Quatro Territórios Rurais no. Redes, v. 15, n. 1, p. 104-127, 2010. 
ANEXO A

\begin{tabular}{|c|c|c|}
\hline ANO & TÍTULO & AUTORES \\
\hline 2010 & $\begin{array}{l}\text { Relação entre o nível de divulgação ambiental e o } \\
\text { desempenho ambiental das empresas componentes do } \\
\text { índice BOVESPA }\end{array}$ & $\begin{array}{l}\text { Michael Dias Corrêa, Tatiane Antonovz, Luiz } \\
\text { Panhoca, Márcia Maria dos Santos BortolocciEspejo }\end{array}$ \\
\hline 2010 & $\begin{array}{l}\text { Um Aporte ao Sistema Contábil Gerencial Ambiental: } \\
\text { Segunda Geração de Indicadores }\end{array}$ & $\begin{array}{l}\text { João Paulo de Oliveira Nunes, Elisete } \\
\text { DahmerPfitscher, Enise Barth Teixeira, Luiz } \\
\text { Alberton, Elisa Elena Espindola }\end{array}$ \\
\hline 2010 & $\begin{array}{l}\text { Passivos Ambientais com Base nos Relatórios de Impacto } \\
\text { Ambiental: Um Estudo das Atividades de Energia } \\
\text { Hidrelétrica de Santa Catarina }\end{array}$ & $\begin{array}{l}\text { Christiano Coelho, Ana Lúcia de Araújo Lima } \\
\text { Coelho, Anderson Dorow }\end{array}$ \\
\hline 2010 & $\begin{array}{l}\text { ICMS Ecológico e Pagamento por Serviços Ambientais } \\
\text { (PSA) na Amazônia }\end{array}$ & Ynis Cristine de S. M. L. Ferreira, Mário Vasconcellos \\
\hline 2011 & $\begin{array}{l}\text { Utilização da Demonstração do Valor Adicionado como } \\
\text { Ferramenta Estratégica de Avaliação: Uma Investigação } \\
\text { nos Sindicatos }\end{array}$ & $\begin{array}{l}\text { Luiz Carlos Miranda, Suênia Graziella Oliveira de } \\
\text { Almeida Santos do Nascimento, Umbelina Cravo } \\
\text { Teixeira Lagioia, Jeronymo José Libonati }\end{array}$ \\
\hline 2011 & $\begin{array}{l}\text { Social Disclosure e Custo de Capital Próprio em Empresas } \\
\text { Brasileiras de Capital Aberto }\end{array}$ & $\begin{array}{l}\text { Rodrigo de Souza Gonçalves, Otávio Ribeiro de } \\
\text { Medeiros }\end{array}$ \\
\hline 2011 & $\begin{array}{l}\text { Proposta para Avaliação e Validação do Social Disclosure } \\
\text { dos Programas Sociais Externos }\end{array}$ & $\begin{array}{l}\text { Rodrigo de Souza Gonçalves, Otávio Ribeiro de } \\
\text { Medeiros, Jorge KatsumiNiyama, Elionor Farah } \\
\text { JreigeWeffort }\end{array}$ \\
\hline 2011 & Diálogo IFRS e GRI para o Desenvolvimento Sustentável & José Roberto Kassai, Helisa Ha, L. Nelson Carvalho \\
\hline 2011 & Sustentabilidade: Economia e Ecologia Sustentáveis? & Eloy Antônio Fenker, Elaine Ferreira \\
\hline 2011 & $\begin{array}{l}\text { Relatórios de Responsabilidade Social Corporativa no } \\
\text { Brasil e no México: O Poder da Indústria Local }\end{array}$ & Laura Calixto \\
\hline 2011 & $\begin{array}{l}\text { Relatórios de Sustentabilidade: Um Estudo Longitudinal } \\
\text { Sobre a Divulgação em três países Latino-Americanos }\end{array}$ & Laura Calixto \\
\hline 2011 & $\begin{array}{l}\text { A Influência da Origem do Controle Acionário no Nível } \\
\text { de Disclosure Ambiental no Setor de Energia Elétrica No } \\
\text { Brasil }\end{array}$ & $\begin{array}{l}\text { Célia Braga, Ariovaldo dos Santos, Patrícia Pereira } \\
\text { da Silva, Rosângela Venâncio Nunes }\end{array}$ \\
\hline 2011 & $\begin{array}{l}\text { Controladoria e Responsabilidade Social Empresarial: } \\
\text { Estudo nas Empresas Ganhadoras do Prêmio Delmiro } \\
\text { Gouveia }\end{array}$ & $\begin{array}{l}\text { Mônica Valeska Veras Machado, Maria da Glória } \\
\text { Arrais Peter, Marcus Vinicius Veras Machado, } \\
\text { Talyta Eduardo Oliveira }\end{array}$ \\
\hline 2011 & $\begin{array}{l}\text { Indicadores Sociais Internos e a Geração de Valor } \\
\text { Adicionado: uma análise da relação do Balanço Social } \\
\text { e da Demonstração do Valor Adicionado em bancos } \\
\text { brasileiros }\end{array}$ & $\begin{array}{l}\text { Silvane Maria Taiarol, Simone Letícia Raimundini, } \\
\text { Ariel Behr }\end{array}$ \\
\hline 2011 & $\begin{array}{l}\text { Créditos de Carbono e as Divergências Contábeis } \\
\text { e Tributárias: Análise do Contexto Regulatório da } \\
\text { Comercialização de Créditos de Carbono oriundos de } \\
\text { Projetos de Mecanismo de Desenvolvimento Limpo } \\
\text { (MDL) no Mercado de Carbono Brasileiro }\end{array}$ & $\begin{array}{l}\text { André Luis Rocha de Souza, Guinevere Alvarez } \\
\text { Machado de Melo Gomes }\end{array}$ \\
\hline 2011 & $\begin{array}{l}\text { Sustentabilidade em Instituições Financeiras no Brasil: } \\
\text { uma análise sob a ótica da global reportinginitiative-GRI }\end{array}$ & Ana Cristina de Faria, Elaine PetilNogueira \\
\hline 2011 & $\begin{array}{l}\text { Evidenciação Ambiental: resíduos sólidos de empresas } \\
\text { de papel e celulose }\end{array}$ & $\begin{array}{l}\text { Barbara de Lima Voss, Elisete DahmerPfitscher, } \\
\text { Bernadete Limongi }\end{array}$ \\
\hline 2012 & $\begin{array}{l}\text { Evidenciação Ambiental dos Resíduos Sólidos de } \\
\text { Empresas Brasileiras Potencialmente Poluidoras }\end{array}$ & $\begin{array}{l}\text { Barbara de Lima Voss, Elisete DahmerPfitscher, } \\
\text { Maisa de Souza Ribeiro }\end{array}$ \\
\hline 2012 & $\begin{array}{l}\text { Intensidade da Evidenciação da Responsabilidade Social: } \\
\text { Um Estudo Comparativo entre Empresas Brasileiras e } \\
\text { Espanholas }\end{array}$ & Ernani Ott, Letícia Goulart dos Santos Tessmann \\
\hline
\end{tabular}


Valoração Econômica de Dano Ambiental: visão

2012 Econômica Contábil para o Caso do Estaleiro Atlântico Sul

Análise do Retorno Anormal das Empresas Winners e

2012 Losers Participantes ou Não do Índice de Sustentabilidade Empresarial (ISE): Um estudo empírico na BM\&FBOVESPA

Qualidade de Evidenciação de Informações Ambientais:

2012 Proposta de um Indicador a Partir da Percepção de Especialistas

A Relação entre o Disclosure Ambiental e Retorno

2012 Anormal: uma análise das empresas brasileiras listadas na Bovespa

Sustentabilidade tem valor? Uma investigação no mercado de capitais brasileiro

Divulgação do Relatório de Sustentabilidade e Custo de Capital Próprio de Companhias Abertas no Brasil

Os Efeitos da Reputação Corporativa no Custo de Capital

2014 Próprio em Empresas Brasileiras Listadas

Métrica de Valoração Ambiental: uma Percepção da Gestão Pública no Município de Cavalcante

2014 Assistências Governamentais e Disclosure Socioambiental

Fatores Determinantes da Reputação Corporativa nas Companhias Abertas do Brasil

2015 Fatores Determinantes do Disclosure do Capital Humano

Qualidade da Informação Contábil e Sustentabilidade:

2015 um Estudo nas Companhias Brasileiras Listadas na Gildo Rodrigues da Silva, Fábio Moraes da Costa BM\&FBovespa

Análise do Nível de Aderência das Companhias de

2015 Energia Elétrica às Recomendações de Evidenciação Ambiental da Global ReportingInitiative (GRI)

2015 Determinantes de Disclosure dos Riscos Climáticos nos Relatórios Anuais das Empresas Brasileiras

Alocação de Valor ao Stakeholder Funcionário e o Efeito na Competitividade e na Produtividade do Setor Bancário

2016 Relato Integrado: Divulgação dos Capitais segundo o Isomorfismo Institucional

Evidenciação Ambiental: Análise dos Recursos Alessandra Rodrigues Machado de

2016 Hídricos com Base nos Indicadores do Relatório de Araujo, Luiz Felipe Ferreira, Suliani Rover, Sustentabilidade da Global ReportingInitiative (GRI)

Empresas Potencialmente Poluidoras: as Variáveis

2016 Determinantes Que Influenciam a Divulgação Voluntária Ambiental

Análise Exploratória da Metodologia Utilizada pelo

2016 Índice de Carbono Eficiente da Bolsa de Mercadoria e Futuros da Bolsa de Valores de São Paulo
Silvana Karina de Melo Travassos, José Isidio de Freitas Costa, Josenildo dos Santos

Sueli Gonçalves da Silva Maia, Valcemiro Nossa, Silvania NerisNossa

Ramon KaelBenassiBachmann, Leandro Marcondes Carneiro, Marcia Maria dos Santos BortolocciEspejo

Sheila Mendes Fernandes

Valdir de Jesus Lameira, Walter Lee Ness Junior, Osvaldo Luis Gonçalves Quelhas, Roberto Guimarães Pereira

Suliani Rover, Ariovaldo dos Santos

zabela Paranaíba Calegari, Rodrigo de Souza Gonçalves

Fernanda Jaqueline Lopes, Fátima de Souza Freire Islane Vidal Fonteles, Vera Maria Rodrigues Ponte, Marcelle Colares Oliveira, Maísa de Souza Ribeiro Alan Diógenes Góis, Márcia Martins Mendes De Luca, Alessandra Carvalho de Vasconcelos, Gerlando Augusto Sampaio Franco de Lima

Alan Diógenes Góis, Márcia Martins Mendes De Luca, José Airton Alcantara Monte Júnior

Márcia Gomes dos Santos, José Roberto de Souza Francisco

Daniel Kouloukoui, Sonia Maria da Silva Gomes, José Bernardo Cordeiro Filho, Gisele Ferreira Tiryaki, Nverson da Cruz Oliveira

Isac de Freitas Brandão, Andressa Silva Miranda Diógenes, Mônica Cavalcanti Sá de Abreu

David Stanhy de Carvalho Silva, Marcelle Colares Oliveira, Carlos Adriano Santos Gomes

DenizeDemarcheMinattiFerreira

RafaelePotrich, MarcildeSabadin, Rodrigo Angonese, André da Silva Pereira

Francisco Santana de Sousa, Dirceu da Silva, Edna de Souza Machado Santos, Alba Zucco 